Research Article

\title{
The Expression of Seismic Surrounding Rock Pressure for a Shallow Tunnel Is Derived Using the Pseudostatic Method
}

\author{
Zhengde Wei $(i)$ and Yanpeng Zhu \\ School of Civil Engineering, Lanzhou University of Technology, Lanzhou, Gansu 730050, China \\ Correspondence should be addressed to Zhengde Wei; 382526552@qq.com
}

Received 2 December 2020; Revised 22 December 2020; Accepted 3 January 2021; Published 9 January 2021

Academic Editor: Mingfeng Lei

Copyright (C) 2021 Zhengde Wei and Yanpeng Zhu. This is an open access article distributed under the Creative Commons Attribution License, which permits unrestricted use, distribution, and reproduction in any medium, provided the original work is properly cited.

\begin{abstract}
Terzaghi developed a generalized expression of the vertical surrounding rock pressures of shallow tunnels by considering the limit equilibrium of soil masses. In this paper, based on the Terzaghi failure mode, the pseudostatic method is used to derive this expression under seismic loading conditions. The surrounding rock in the fractured zone of the tunnel side wall is analyzed as an isolated body using the limit equilibrium method to obtain the explicit calculation expressions of the horizontal surrounding rock pressures of a shallow tunnel under seismic loading. Case analysis indicates that the proposed method is feasible. In addition, the influence of the seismic acceleration coefficient on surrounding rock pressures is further discussed. The results show that the horizontal surrounding rock pressure decreases with the increase of seismic acceleration coefficients. The vertical surrounding rock pressure increases as the horizontal seismic acceleration coefficient increases, and it decreases with the increase of the vertical seismic acceleration coefficient, and the effect of the seismic acceleration coefficient on surrounding rock pressure is significant. The study results can provide reference for the seismic safety evaluation and structural seismic design of shallow tunnels.
\end{abstract}

\section{Introduction}

After the tunnel excavation, due to the deformation and relaxation of surrounding rock, the pressure acting on the tunnel lining structures is called the surrounding rock pressure, which is the main load of the supporting structure and is also an important basis for the design of tunnel lining structure by using the load structure method. At present, the calculation methods for the surrounding rock pressure of shallow tunnels mainly include Terzaghi theory [1], Bierbäumer theory [2], and the main methods recommended in the railway and road tunnel design code of China [3, 4]. However, due to the limitations of various environmental conditions and technical means, there are still many deficiencies in the abovementioned methods, especially for shallow buried tunnels. For instance, the influences of overlying strata by seepage, excavation disturbance, earthquake, and other external conditions are not considered.

It is generally believed that the tunnel should have stronger performance than the grounds buildings.
Therefore, the seismic of tunnels is not paid attention all the time $[5,6]$. However, in fact, the impact of earthquakes on tunnels cannot be ignored. The Tangshan earthquake in 1976, the Osaka-Kobe earthquake in 1995, the Jiji earthquake in 1999, and the Wenchuan earthquake in 2008 all brought great disasters to the tunnels near the epicenter [7-9].

In recent years, many scholars have carried out efforts considering the impact of earthquakes. Navarro and Samartn [10] used the finite difference method to derive the analytical solution of tunnel internal force. Sanchez Merino et al. [11] studied the simple longitudinal seismic response of tunnel lining to surface wave. Kouretzis et al. [12] studied the influence of soil lining interface friction on the circumferential force and bending moment of tunnel lining under the action of $S$ wave and $P$ wave through numerical simulation. Zhang et al. [13] studied the influence of horizontal and vertical seismic forces on the stability of shallow tunnels using the pseudostatic method. These methods are commonly used to calculate the internal force of the tunnel 
structure and the stability of surrounding rock, but the calculation of mechanical performances of surrounding rock around the tunnel is not mentioned.

Taking a two-lane highway tunnel in grade IV surrounding rock as an example, Yang et al. [14] proposed a pseudostatic method for seismic response calculation of highway tunnels by regarding the lining structure as a frame structure on elastic foundation. Based on the pseudostatic method, Bai et al. [15] derived the analytical solution of surrounding rock pressure of the shallow buried unsymmetrical pressure tunnel under earthquake action through rotation of seismic force deflection angle and limit equilibrium condition. Sun and Dias [16] studied the seismic response of a circular tunnel considering the stress release of surrounding soil due to excavation by using the pseudostatic analysis method. On the basis of considering the influence of horizontal seismic force, Yang et al. [17] studied the surrounding rock pressure of the shallow buried unsymmetrical pressure tunnel, but only considered the horizontal seismic force, ignoring the influence of vertical seismic force. In all of these seismic impact studies, it was assumed that the seismic forces were pseudostatic in nature. Numerical simulation and experimental studies [18-22] showed that the horizontal surrounding rock pressure was nonlinear. The pseudostatic method does not provide a simple and clear analytical expression for the horizontal surrounding rock pressures.

In addition, the researchers also used the dynamic response analysis method to explore the problem in depth [23-26]. However, the dynamic response analysis method needs to input the acceleration time history curve of seismic wave, and thus, the calculation analysis is more complex. Although it has many advantages, it is not convenient for engineering designers. Therefore, the pseudostatic analysis method, which has clear mechanical concept and can directly obtain the results through, is more widely used in the conventional tunnel seismic surrounding rock pressure analysis.

In the calculation of surrounding rock pressure, the result of Bierbäumer theory [2] is too small, and the code method [3, 4] makes a lot of artificial assumptions and lacks sufficient theoretical basis. At present, the classical Terzaghi method is widely used, and its failure mode and analysis method provide acceptable calculation results. Recently, literature $[27,28]$ have also discussed this issue in depth. It is proved that the Terzaghi method is more suitable for shallow tunnels with poor surrounding rock conditions. In this study, it is proposed to adopt the destructive mode of Terzaghi in order to simplify the calculation.

In this paper, an attempt is made to derive the analytical expressions of seismic surrounding rock pressure using a relatively simple pseudostatic approach, based on the Terzaghi failure mode, and through the limit equilibrium stress analysis. In particular, the horizontal pressure of surrounding rock under seismic action is discussed, hoping to supplement and perfect the methods proposed in existing research achievements.

\section{Basic Theory}

2.1. Terzaghi Failure Mode. Terzaghi believed that all soils were cut by joints and fissures to varying degrees, so the soil body can be regarded as granular. After excavation, the soil body above the tunnel would sink with the deformation of the tunnel. Two shear planes appeared between the sides of the tunnel and the ground surface, and stress transfer occurred as soil particles rip one another. As a result, the vertical surrounding rock pressure acting on the lining was induced by stress transfer. It was assumed that the vertical compressive stress acting on any horizontal plane was uniform. Terzaghi theory used to calculate the surrounding rock was based on the limit equilibrium method. The failure mode is shown in Figure 1, where $\sigma_{v}$ means the vertical stress at depth $h ; \varphi_{0}$ means the estimation friction angle; $\theta$ means the rupture angle of the surrounding rock, and $\lambda$ is the lateral pressure coefficient of the overlying stratum, which is calculated by $\lambda=1.0$ to 1.6 as suggested by the Terzaghi experimental results.

2.2. Pseudostatic Method. The physical concept of the pseudostatic method is simple and clear, the calculation steps are convenient, and it is widely used in practical engineering practice. It is an approximate simple method to solve the dynamic problem by the static method. The core idea is to replace the effect of the seismic load with the constant inertial force in the horizontal and vertical directions. The direction of application is taken as the most unfavorable direction to the structure. The horizontal and vertical inertia forces generated during ground motion are presented as follows:

$$
\left\{\begin{array}{l}
F_{h}=\frac{\alpha_{h} G}{g}=k_{h} G, \\
F_{v}=\frac{\alpha_{v} G}{g}=k_{v} G,
\end{array}\right.
$$

where $\alpha_{h}$ and $\alpha_{v}$ are the pseudostatic accelerations in the horizontal and vertical directions, respectively; $k_{h}$ and $k_{v}$ are the pseudostatic acceleration coefficients in the horizontal and vertical directions, respectively; $G$ is the weight of the soil mass; and $g$ is the gravitational acceleration. When the seismic intensity is designed to be VI, VII, VIII, and IX degrees, the horizontal seismic acceleration coefficients $k_{h}$ are taken as $0.05,0.10,0.20$, and 0.40 , respectively, and $k_{v}$ can be obtained by $k_{v}=(1 / 2 \sim t 2 / 3) k_{h}[11]$.

\section{Analytical Solution of Surrounding Rock Pressure under Earthquake Action}

3.1. Model Parameters. As shown in Figure 2, assuming that the soil is a uniform stratum, the horizontal slice element of thickness $d h$ is used to calculate the equilibrium of forces. $P_{1}=L \sigma_{v} ; \quad T_{1}=L\left(\sigma_{v}+\mathrm{d} \sigma_{v}\right) ; \quad F_{1}=\lambda \sigma_{v} \tan \varphi_{0} \mathrm{~d} h ; \quad$ and $N_{1}=\lambda \sigma_{v} \mathrm{~d} h$.

When an earthquake occurs, the soil mass is affected by the seismic load. According to the pseudostatic method, the horizontal and vertical directions of the soil mass will produce inertial forces $k_{h} G_{1}[\longleftarrow+, \longrightarrow-]$ and $k_{v} G_{1}[\uparrow+, \downarrow$ $-]$, respectively, where $k_{h}$ and $k_{v}$ are the pseudostatic 


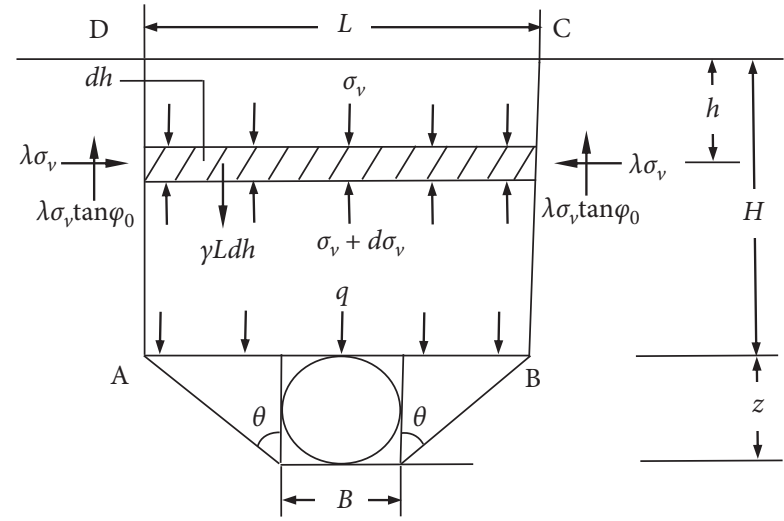

FIgURe 1: Terzaghi failure mode.

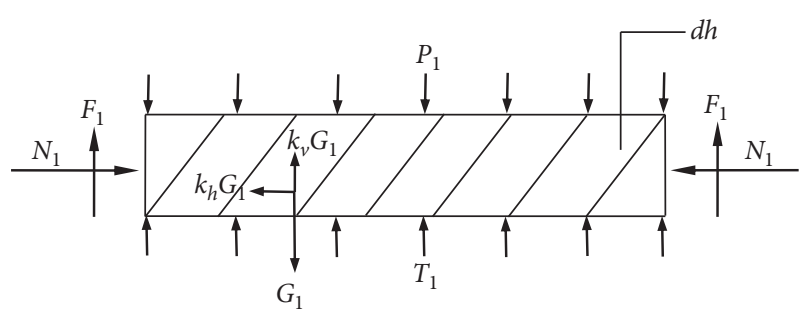

FIGURE 2: Force diagram of the microunit.

acceleration coefficients in the horizontal and vertical directions, respectively; $G_{1}$ is the self-weight of the microunit; and $g$ means gravitational acceleration. The force analysis diagram is shown in Figure 3(a). The inertial forces $k_{h} G_{1}$ and $k_{v} G_{1}$ are regarded as the static force, and the soil gravity $G_{1}$ is combined to obtain the resultant force $G_{1}^{\prime}$, wherein the angle between $G_{1}^{\prime}$ and the vertical line is $\eta$, as shown in Figure 3(b). $\eta$ is the deflection angle of earthquake force.

According to reference [29],

$$
\eta=\arctan \frac{k_{h}}{1-k_{v}} .
$$

It is easy to know from geometric relations that

$$
G_{1}^{\prime}=\left(1-k_{v}\right) G_{1} \sec \eta \text {. }
$$

The self-weight of the micro unit is

$$
G_{1}=\gamma L \mathrm{~d} h .
$$

3.2. Analytical Solution of Vertical Surrounding Rock Pressures. The vertical equilibrium of the microunit $\mathrm{d} h$ at $h$ depth, as shown in Figures 2 and 3(c), is analyzed as follows:

$$
P_{1} \cos \eta+G_{1}^{\prime}=T_{1} \cos \eta+2 F_{1} \cos \eta \text {. }
$$

Substituting equation (4) and other parameters into equation (5) yields

$$
\begin{aligned}
L \sigma_{v} \cos \eta+\gamma L \mathrm{~d} h\left(1-k_{v}\right) \sec \eta= & \left(\sigma_{v}+\mathrm{d} \sigma_{v}\right) L \cos \eta \\
& +2 \lambda \sigma_{v} \tan \varphi_{0} \cos \eta \mathrm{d} h .
\end{aligned}
$$

We transform this equation as

$$
\frac{\mathrm{d} \sigma_{v}}{\mathrm{~d} h}+\frac{2 \lambda \sigma_{v} \tan \varphi_{0}}{L}=\gamma\left(1-k_{v}\right) \sec ^{2} \eta,
$$

where $L=B+2 z \tan \theta ; B$ is the excavation breadth of the tunnel.

Equation (7) determines the vertical stress at any depth:

$$
\sigma_{v}(h)=\frac{L \gamma\left(1-k_{v}\right) \sec ^{2} \eta}{2 \lambda \tan \varphi_{0}}\left[1+A \exp \left(-\frac{2 \lambda \tan \varphi_{0}}{L} h\right)\right],
$$

where $A$ is an undetermined parameter determined by the boundary condition. When the boundary condition $h=0$, $\sigma_{v}=0$ (no load on the ground surface) is substituted into equation (8) to get $A=-1$; thereby,

$$
\sigma_{v}(h)=\frac{L \gamma\left(1-k_{v}\right) \sec ^{2} \eta}{2 \lambda \tan \varphi_{0}}\left[1-\exp \left(-\frac{2 \lambda \tan \varphi_{0}}{L} h\right)\right] .
$$

When $h=H$, the vertical pressure acting on the top of tunnel $A B$ is obtained using equation (9):

$$
q=\left.\sigma_{v}(h)\right|_{h=H}=\frac{L \gamma\left(1-k_{v}\right) \sec ^{2} \eta}{2 \lambda \tan \varphi_{0}}\left[1-\exp \left(-\frac{2 H \lambda \tan \varphi_{0}}{L}\right)\right],
$$

where $H$ is the buried depth of the tunnel. This equation is the computational formula of vertical surrounding rock pressure of the tunnel under earthquake action.

3.3. Analytical Solution of Horizontal Surrounding Rock Pressures. The triangle slider at the tunnel side is taken into force analysis, assuming that the resultant supporting resistance supplied by the supporting structure that maintains the stability of tunnel surrounding rock is $F_{2}$. The acting direction between the resultant supporting resistance and vertical line of the triangle is undoubtedly $\theta+\varphi_{0}$ according to the related flow rule, as shown in Figure 4.

Similarly, according to the geometric relationship, we get

$$
G_{2}^{\prime}=\left(1-k_{v}\right) G_{2} \sec \eta
$$

where $G_{2}$ is the self-weight of the triangle rupture body, which is calculated as

$$
G_{2}=\frac{1}{2} \gamma z^{2} \tan \theta
$$

As shown in Figure 5, based on the static equilibrium condition, 


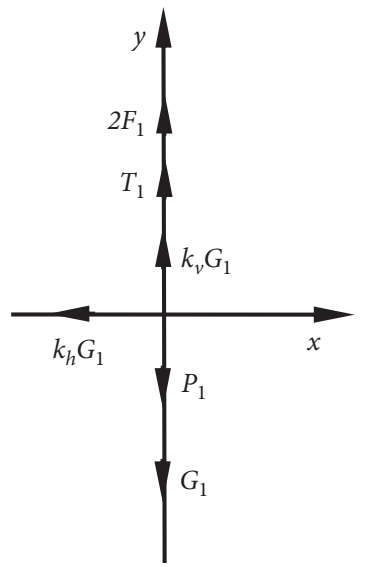

(a)

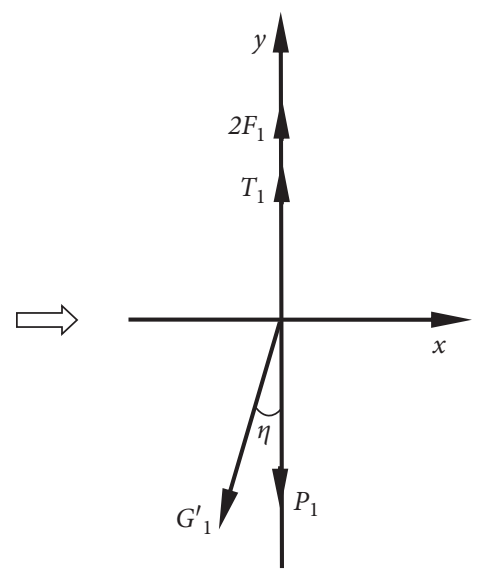

(b)

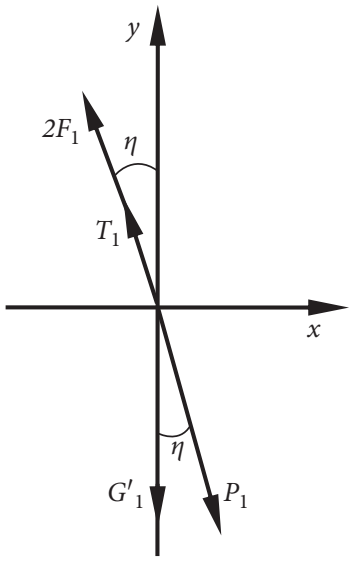

(c)

Figure 3: Calculation diagrams of the microunit. (a) Original force diagram. (b) Composition graph of inertial force and gravity. (c) Force system rotation angle $\eta$.

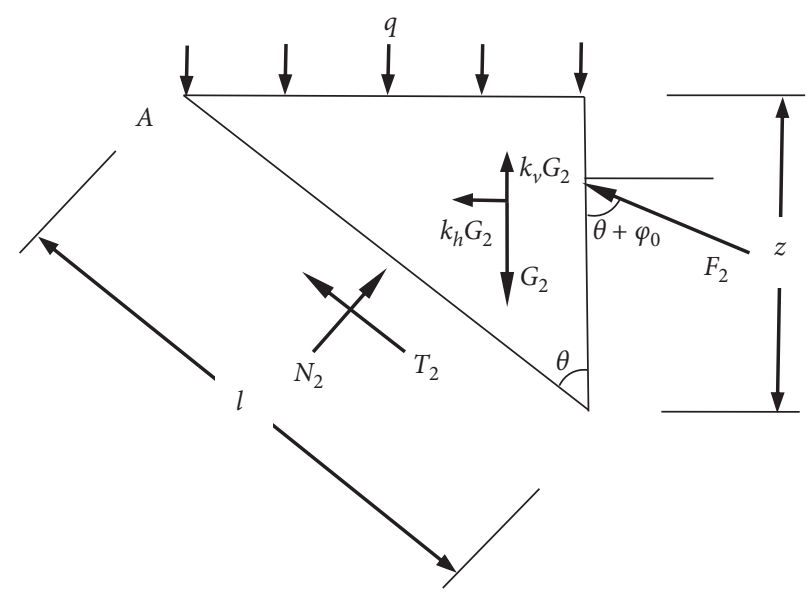

FIGURE 4: Force analysis of the side wall fractured zone.

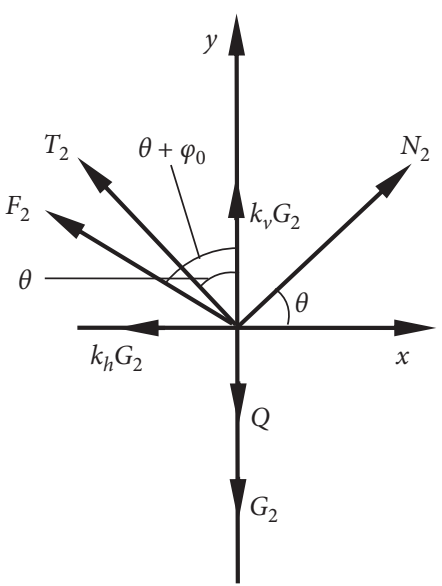

(a)

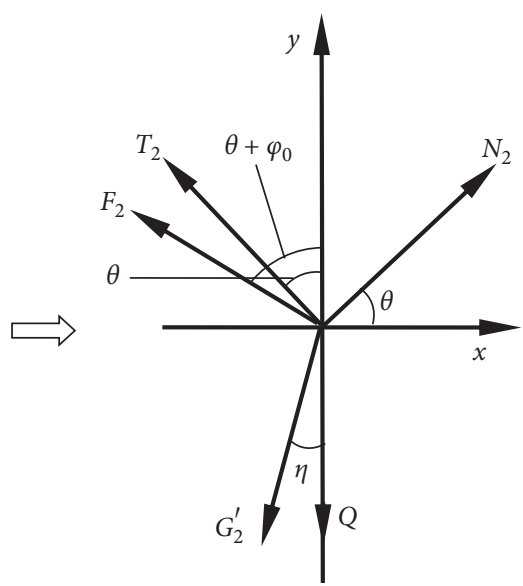

(b)

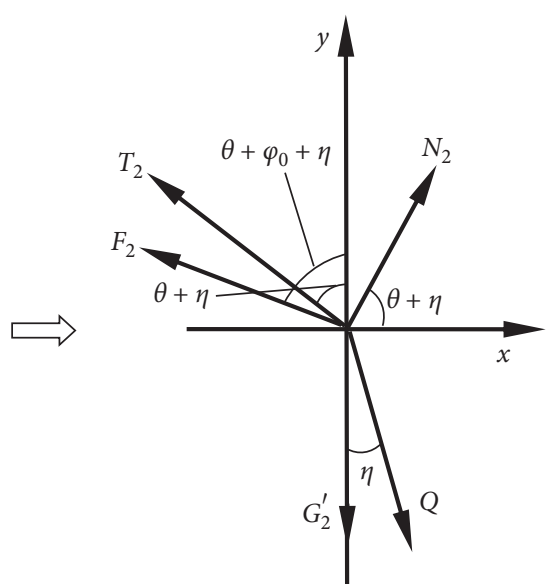

(c)

FIgURE 5: Calculation diagram of the side wall fractured zone. (a) Original force diagram. (b) Composition graph of inertial force and gravity. (c) Force system rotation angle $\eta$. 


$$
\left\{\begin{array}{l}
Q \cos \eta+G_{2}^{\prime}-N_{2} \sin (\theta+\eta)-T_{2} \cos (\theta+\eta)-F_{2} \cos \left(\theta+\varphi_{0}+\eta\right)=0, \\
F_{2} \sin \left(\theta+\varphi_{0}+\eta\right)+T_{2} \sin (\theta+\eta)-N_{2} \cos (\theta+\eta)=0,
\end{array}\right.
$$

where $Q=q z \tan \theta$. The rupture plane satisfies the Mohr-Coulomb yield criteria with

$$
T_{2}=N_{2} \tan \varphi_{0} .
$$

When equations (13) and (14) are simultaneously applied and solved, we derive

$$
F_{2}=\left(q z \tan \theta \cos \eta+G_{2}^{\prime}\right) \cos \left(\theta+\varphi_{0}+\eta\right),
$$

where $\theta=45^{\circ}-\varphi_{0} / 2$.

Thus, the surrounding rock maintains stable horizontal lateral support.

$$
\begin{aligned}
F_{x} & =F_{2} \sin \left(\theta+\varphi_{0}+\eta\right), \\
& =\left(q z \tan \theta \cos \eta+G_{2}^{\prime}\right) \cos \left(\theta+\varphi_{0}+\eta\right) \cdot \sin \left(\theta+\varphi_{0}+\eta\right) .
\end{aligned}
$$

If the horizontal load distributes as the line moves along the vertical direction, then the horizontal surrounding rock pressure in the depth range of the tunnel is

$$
e=\left(q z \tan \theta \cos \eta+G_{2}^{\prime}\right) \cos \left(\theta+\varphi_{0}+\eta\right) \cdot \frac{\sin \left(\theta+\varphi_{0}+\eta\right)}{z} .
$$

Then, we substitute equations (11) and (12) into equation (17), which yields

$$
e=\left[q z \tan \theta \cos \eta+\frac{1}{2}\left(1-k_{v}\right) \gamma z^{2} \tan \theta \sec \eta\right] \cos \left(\theta+\varphi_{0}+\eta\right) \cdot \frac{\sin \left(\theta+\varphi_{0}+\eta\right)}{z} .
$$

This equation is the formula of horizontal surrounding rock pressure of the tunnel under earthquake action.

\section{Verification and Comparison}

The calculation model of the surrounding rock pressure of the shallow tunnel under seismic force is simplified, which provides convenience for seismic design of tunnels. The derived formula needs further verification. In order to verify the formula derived in this paper under earthquake action, that is, the pseudostatic acceleration coefficients $k_{h} \neq 0$ and $k_{v} \neq 0$, the calculation results derived from the proposed model are compared with the results of the shaking table test of Ishibashi and Fang [30] and further compared with the classical dynamic earth pressure Mononobe-Okabe formula $[31,32]$. It should be emphasized that the calculation method for the vertical surrounding rock pressure is similar to Terzaghi theory. Therefore, the comparative analysis is only performed on the horizontal surrounding rock pressure.

Ishibashi and Fang use the siliceous sand from Ottawa, Canada, as fillers. The average density of the sand is $1.643 \mathrm{~g} /$ $\mathrm{cm}^{3}$, internal friction angle $\varphi=40.1^{\circ}, k_{h}=0.215$, and $z=1 \mathrm{~m}$. Mononobe-Okabe's expression is as follows:

$$
e=\frac{1}{2} \cdot \frac{1+k_{v}}{\cos \eta} \gamma H^{2} \frac{\cos ^{2}(\varphi-\alpha-\eta)}{\cos ^{2} \alpha \cos (\alpha+\delta+\eta)[1+\sqrt{((\sin (\varphi+\delta) \sin (\varphi-\beta-\eta)) /(\cos (\alpha+\delta+\eta) \cos (\alpha-\beta)))}]^{2}}
$$

where $\beta=$ inclination to the horizontal of the backfill top surface; $\delta=$ soil-wall interface friction angle, and the retaining wall back surface makes an angle $\alpha$ with vertical. The other parameters are consistent with the previous section.

The parameters in this paper are consistent with the test method, where $\alpha=0, \beta=0$, and $\delta=\varphi$. The calculation results and test results are shown in Figure 6.

It can be seen from the figure that the horizontal surrounding rock pressure is nonlinearly distributed along the tunnel height. Compared with the Mononobe-Okabe method, the results obtained by this method are more consistent with the experimental results. A large number of study results show that the distribution of surrounding rock pressure under earthquake is nonlinear. Therefore, the seismic surrounding rock pressure results obtained in this study are more reasonable than the Mononobe-Okabe theory.

In summary, the analysis method selected in this study is feasible, and the calculation model of surrounding rock pressure of shallow tunnel under horizontal and vertical seismic forces is reasonable. In addition, the surrounding rock pressure model of a shallow tunnel established in the Terzaghi method is a special case of the model proposed in this paper, that is, when the seismic load is 0 . 


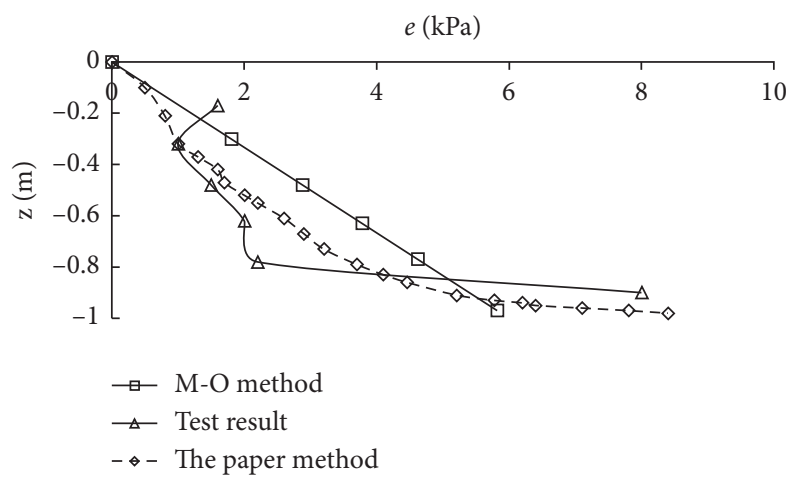

FIGURE 6: Comparison of calculation results and test results.

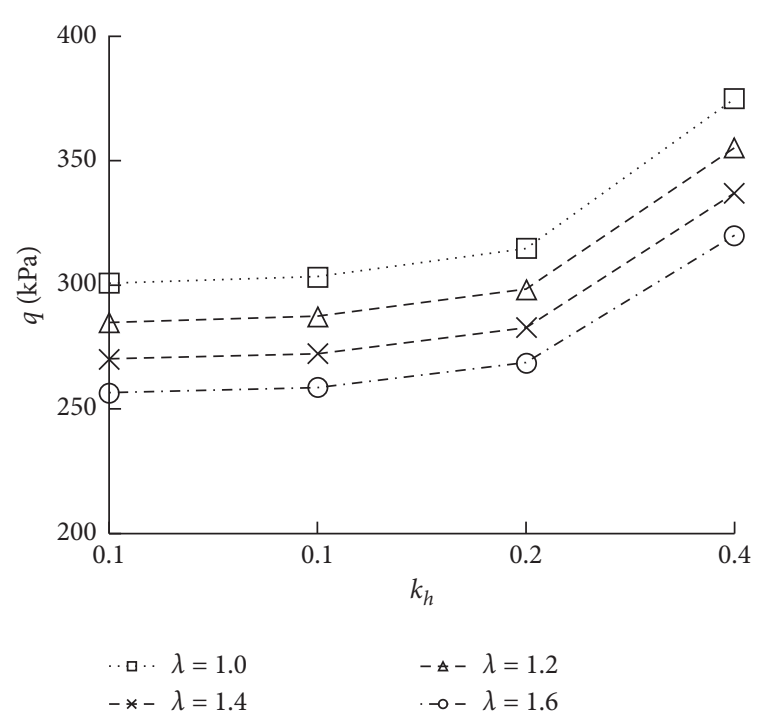

(a)

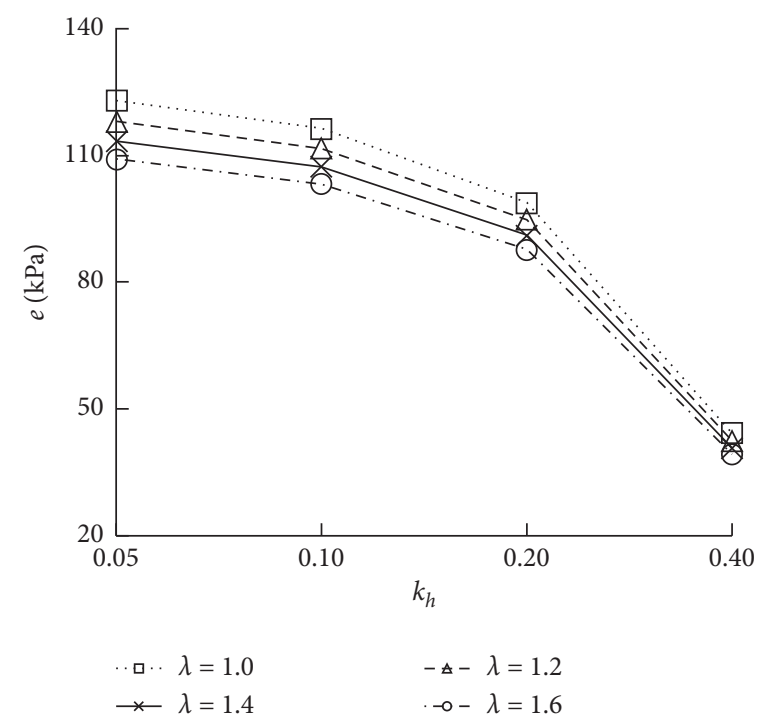

(b)

Figure 7: Influence of $k_{h}$ on surrounding rock pressure. (a) Vertical surrounding rock pressure. (b) Horizontal surrounding rock pressure.

\section{Effect of Earthquake Action}

In order to study the influence of seismic force on the surrounding rock pressure of shallow tunnels, it is assumed that only horizontal seismic forces (case I) and horizontal and vertical seismic forces act together (case II).

5.1. Effect of Horizontal Seismic Force on Surrounding Rock Pressure of a Shallow Tunnel. When there is only horizontal seismic force (the case I), $k_{h} \neq 0$ and $k_{v}=0$. The buried depth of tunnel $H=20 \mathrm{~m}$, tunnel span $B=10 \mathrm{~m}$, height $z=10 \mathrm{~m}$, volume weight of surrounding rock $\gamma=20 \mathrm{kN} / \mathrm{m}^{3}$, estimation friction angle $\varphi_{0}=20^{\circ}$, and the lateral pressure coefficient of overlying strata $\lambda=1.0-1.6$. In order to study the influence of horizontal seismic force on surrounding rock pressure of a shallow tunnel, according to equation (2), the deflection angles of earthquake force $\eta$ are $2.93^{\circ}, 6.00^{\circ}, 12.53^{\circ}$, and $26.57^{\circ}$, respectively. Through calculation, the influence of horizontal seismic acceleration coefficient $k_{h}$ on surrounding rock pressure is shown in Figure 7.
The results of the analysis are as follows.

In the case of horizontal seismic force alone $\left(k_{h} \neq 0\right.$ and $k_{v}=0$ ), the horizontal seismic force has a greater impact on the surrounding rock pressures of shallow tunnels. The vertical surrounding rock pressure significantly increases when the seismic intensity increases. On the contrary, the horizontal surrounding rock pressure significantly decreases when the seismic intensity increases.

When $\lambda$ is constant, the vertical surrounding rock pressure increases with the increase of horizontal seismic acceleration coefficient $k_{h}$. The horizontal surrounding rock pressure decreases with the increase of horizontal seismic acceleration coefficient $k_{h}$. When $k_{h}$ increases from 0.20 to 0.40 , the variation amplitude of surrounding rock pressure is the largest.

5.2. Effect of Comprehensive Seismic Force on Surrounding Rock Pressure of a Shallow Tunnel. When horizontal and vertical seismic forces act simultaneously (the case II), $k_{h} \neq 0$ and $k_{v} \neq 0$. In order to study the influence of vertical seismic 


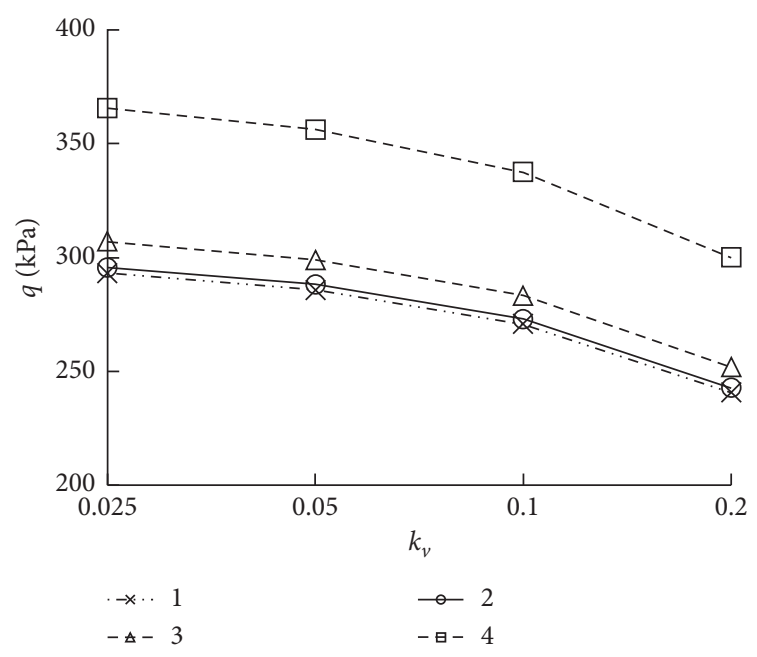

(a)

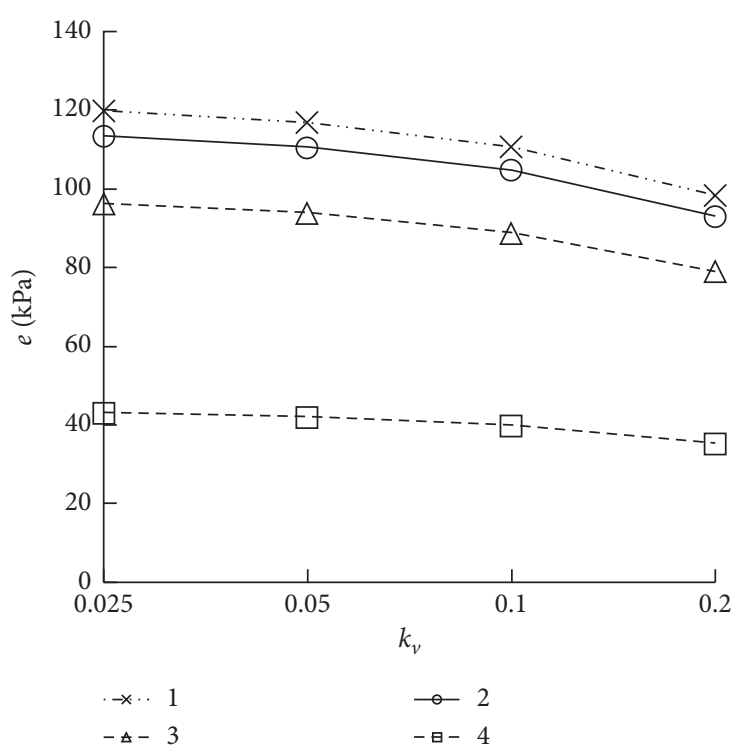

(b)

FIGURE 8: Influence of $k_{h}$ and $k_{v}$ on surrounding rock pressure. $k_{h}: 1-0.05 ; 2-0.10 ; 3-0.20$; and 4-0.40. (a) Vertical surrounding rock pressure. (b) Horizontal surrounding rock pressure.

force on the surrounding rock pressure of a shallow tunnel, the horizontal seismic acceleration coefficients $k_{h}$ are 0.05 , $0.10,0.20$, and 0.40 , respectively. Taking $k_{v}=0.5 k_{h}$, the vertical seismic acceleration coefficients $k_{v}$ are $0.025,0.05$, 0.10 , and 0.20 , respectively.

When $\lambda=1.0-1.6$, the variation law of surrounding rock pressure of the shallow tunnel is approximately the same. In this paper, when $\lambda=1.0$, the surrounding rock pressure corresponding to different seismic acceleration coefficients $k_{h}$ and $k_{v}$ is calculated. The influence curve of the horizontal and vertical seismic acceleration coefficient on surrounding rock pressure is shown in Figure 8.

The results of the analysis are as follows.

Under the combined action of horizontal and vertical seismic forces $\left(k_{h} \neq 0\right.$ and $\left.k_{v} \neq 0\right)$, the vertical surrounding rock pressure increases with the increase of horizontal seismic acceleration coefficient $k_{h}$ and decreases with the increase of vertical seismic acceleration coefficient $k_{v}$, while the horizontal surrounding rock pressure decreases with the increase of $k_{h}$ and $k_{v}$.

In summary, in case I and case II, the horizontal surrounding rock pressure decreases with the increase of seismic acceleration coefficients $\left(k_{h}\right.$ and $\left.k_{v}\right)$, while the vertical surrounding rock pressure increases with the increase of $k_{h}$ and decreases with the increase of $k_{v}$. Therefore, the effect of the seismic acceleration coefficient on surrounding rock pressure is significant.

\section{Conclusions}

A method to calculate the vertical surrounding rock pressure of a shallow buried tunnel under seismic action is presented based on the Terzaghi failure mode. Terzaghi theory, which was limited to the static analysis, is expanded to include the dynamic analysis of seismic action. A limit equilibrium analysis of the surrounding rock bodies in a tunnel side rupture zone is conducted, and the computational expressions of the horizontal surrounding rock pressure under the seismic action are derived by the pseudostatic method. The case study indicates that the method presented in this paper is feasible and perfects the insufficiency of the existing calculation methods of horizontal surrounding rock pressure under earthquake action.

In case I and case II, the horizontal surrounding rock pressure decreases with the increase of the seismic acceleration coefficient, while the vertical surrounding rock pressure increases with the increase of $k_{h}$ and decreases with the increase of $k_{v}$. Therefore, the seismic action has a significant impact on the surrounding rock pressure.

Considering the comprehensive effect of horizontal and vertical seismic forces, this paper provides a theoretical basis for the seismic design of actual tunnel engineering in earthquake-prone areas. At the same time, in future research, the applicability of the analytical algorithm will be further verified.

\section{Data Availability}

The data used to support the findings of this study are included within the article.

\section{Conflicts of Interest}

The authors declare that they have no conflicts of interest.

\section{Acknowledgments}

The authors gratefully acknowledge the financial support of the Ministry of Education Chang jiang Scholars Innovation Team (Grant No. IRT_17R51). 


\section{References}

[1] K. Terzaghi, Theoretical Soil Mechanics, John Wiley \& Sons, New York, NY, USA, 1948.

[2] A. Bierbäumer, Die Dimensionierung Des TunnelmauerwErker, Engelmann, Leipzig, Germany, 1913.

[3] Ministry of Railways of the People's Republic of China, Code For Design On Tunnel Of Railway (TB 10003-2005), China Railway Publishing House, Beijing, China, 2005.

[4] Professional Standards Compilation Group of People's Republic of China, Code For Design Of Road Tunnel (JTG D702004), China Communications Press, Beijing, China, 2004.

[5] X.-L. Yang, "Seismic passive pressures of earth structures by nonlinear optimization," Archive of Applied Mechanics, vol. 81, no. 9, pp. 1195-1202, 2011.

[6] S.-1. Chen and M.-w. Gui, "Seismic performance of tunnel lining of side-by-side and vertically stacked twin-tunnels," Journal of Central South University of Technology, vol. 18, no. 4, pp. 1226-1234, 2011.

[7] U. Cilingir and S. P. G. Madabhushi, "Effect of depth on the seismic response of square tunnels," Soils and Foundations, vol. 51, no. 3, pp. 449-457, 2011.

[8] Z. Saada, S. Maghous, and D. Garnier, "Pseudo-static analysis of tunnel face stability using the generalized Hoek-Brown strength criterion," International Journal for Numerical and Analytical Methods in Geomechanics, vol. 37, no. 18, pp. 3194-3212, 2013.

[9] Z. Wang, B. Gao, Y. Jiang, and S. Yuan, "Investigation and assessment on mountain tunnels and geotechnical damage after the Wenchuan earthquake," Science in China Series E: Technological Sciences, vol. 52, no. 2, pp. 546-558, 2009.

[10] C. Navarro and A. Samartn, "Simplified longitudinal seismic analysis of buried tunnels," Software Engineering Workstations, vol. 4, no. 1, pp. 3-10, 1988.

[11] A. L. Sánchez-Merino, J. Fernández-Sáez, and C. Navarro, "Simplified longitudinal seismic response of tunnels linings subjected to surface waves," Soil Dynamics and Earthquake Engineering, vol. 29, no. 3, pp. 579-582, 2009.

[12] G. P. Kouretzis, S. W. Sloan, and J. P. Carter, "Effect of interface friction on tunnel liner internal forces due to seismic $S$ and P-wave propagation," Soil Dynamics and Earthquake Engineering, vol. 46, pp. 41-51, 2013.

[13] J. H. Zhang, X. L. Yang, and B. Zhang, "Upper bound quasistatic analysis of dynamic stability on shallow tunnel under earthquake action," Journal of Central South University (Science and Technology), vol. 46, no. 1, pp. 238-247, 2015.

[14] L. D. Yang, T. Sui, and P. Liu, "Quasi-static calculation method of seismic response of highway tunnel," Journal of Yangtze River Scientific Research Institute, vol. 29, no. 9, pp. 59-63, 2012.

[15] Z. Bai, S. C. Wu, B. Liu et al., "Analytical solution of rock pressure for shallow-buried unsymmetrical-loading tunnels under earthquake loading," Journal of University of Science and Technology Beijing, vol. 35, no. 8, pp. 1106-1112, 2013.

[16] Q. Q. Sun and D. Dias, "Assessment of stress relief during excavation on the seismic tunnel response by the pseudostatic method," Soil Dynamics and Earthquake Engineering, vol. 117, pp. 384-397, 2019.

[17] X. Yang, B. Huang, and Z. Wang, "Rock failure pressure of shallow tunnel subjected to horizontal seismic and unsymmetrical loads," Journal of Central South University (Science and Technology), vol. 41, no. 3, pp. 1096-1095, 2010.
[18] M. Varma, V. B. Maji, and A. Boominathan, "Numerical modeling of a tunnel in jointed rocks subjected to seismic loading," Underground Space, vol. 4, no. 2, pp. 133-146, 2019.

[19] C.-H. Chen, T.-T. Wang, F.-S. Jeng, and T.-H. Huang, "Mechanisms causing seismic damage of tunnels at different depths," Tunnelling and Underground Space Technology, vol. 28, pp. 31-40, 2012.

[20] N.-A. Do, D. Dias, P. Oreste, and I. Djeran-Maigre, "2D numerical investigation of segmental tunnel lining under seismic loading," Soil Dynamics and Earthquake Engineering, vol. 72, pp. 66-76, 2015.

[21] L. Zhang and Y. Liu, "Numerical investigations on the seismic response of a subway tunnel embedded in spatially random clays," Underground Space, vol. 5, no. 1, pp. 43-52, 2020.

[22] Y. Miao, E. Yao, B. Ruan, and H. Zhuang, "Seismic response of shield tunnel subjected to spatially varying earthquake ground motions," Tunnelling and Underground Space Technology, vol. 77, pp. 216-226, 2018.

[23] J. H. Ding, X. L. Jin, Y. Z. Guo et al., "Three-dimensional numerical simulation method and its application to seismic response of shield tunnel," Chinese Journal of Rock Mechanics and Engineering, vol. 25, no. 7, pp. 1430-1436, 2006.

[24] Z. X. Su and C. He, "Shell-spring-contact model for shield tunnel segmental lining analysis and its application," Engineering Mechanics, vol. 24, no. 10, pp. 231-235, 2007.

[25] G. B. Liu, K. H. Xie, and Z. Y. Shi, "Soil-structure interaction of a deep circular tunnel in viscoelastic saturated soil," Engineering Mechanics, vol. 22, no. 6, pp. 148-154, 2005.

[26] J. B. Liu, W. H. Wang, and D. D. Zhao, "Comparison of the pseudo-static methods for seismic analysis of the underground structures," Engineering Mechanics, vol. 30, no. 1, pp. 105-111, 2013.

[27] T. Wan, P. Li, H. Zheng, and M. Zhang, "An analytical model of loosening earth pressure in front of tunnel face for deepburied shield tunnels in sand," Computers and Geotechnics, vol. 115, p. 103170, 2019.

[28] P. Li, F. Wang, L. Fan, H. Wang, and G. Ma, "Analytical scrutiny of loosening pressure on deep twin-tunnels in rock formations," Tunnelling and Underground Space Technology, vol. 83, pp. 373-380, 2019.

[29] D. Y. Xie, Soil Dynamics, Higher Education Press, Beijing, China, 2011.

[30] I. Ishibashi and Y.-S. Fang, "Dynamic earth pressures with different wall movement modes," Soils and Foundations, vol. 27, no. 4, pp. 11-22, 1987.

[31] N. Mononobe, "On determination of earth pressure during earthquake," in Proceeding of the World Engineering Congress, pp. 177-185, Tokyo, Japan, July 1929.

[32] S. Okabe, "General theory on earth pressure and seismic stability of retaining wall and dam," Journal of the Japan Society of Civil Engineers, vol. 10, no. 6, pp. 1277-1323, 1924. 